Laboratorio de Arte, 7-1994 http://dx.doi.org/10.12795/LA.1994.i07.16

\title{
LA "LAMENTACIÓN" DEL IMAGINERO PEDRO MILLÁN EN EL MUSEO DEL ERMITAGE
}

\author{
por María Fernanda Morón de Castro
}

La Lamentación de Pedro Millán, llamada también Grupo de la Piedad o Llanto sobre Cristo muerto, se consideraba desaparecida por tierras de la antigua Rusia. Las vicisitudes sufridas por la escultura desde que salió de la Catedral de Sevilla plantean lo fácil que le ha sido convertirse en una obra anónima en el extranjero, perdiendo allí todo rastro de memoria histórica.

La última persona en analizarla fue Elías Tormo ' que en el año 1911 consiguió dar con su paradero en el Palacio de Mánnol de San Petesburgo, propiedad del Gran Duque Constantino de Rusia, gracias a la ayuda que le brindó el pintor ruso Von Liphart y el arquitecto ruso italiano conservador del edificio. Relata Tormo que en aquella suntuosa mansión repleta de pinturas no constaba dato alguno sobre una escultura de Pedro Millán. Tras grandes esfuerzos se localizó el grupo escultórico de La Lamentación, pero aparecía clasificada como una obra de la escuela alemana.

Los intentos posteriores de localización de esta escultura fueron realizados por Florentino Pérez-Embid y resultaron infructuosos. La Revolución de Octubre de 1917, que llevó consigo la nacionalización de todas las colecciones rusas de carácter privado, hacía presuponer que el grupo escultórico de la Lamentación podría haber sido depositado en el Museo del Ermitage de Leningrado, ya que el Palacio de Mármol, donde pudo verla Elías Tormo, quedó convertido en Museo de Lenin en 1937. Las reiteradas revisiones de catálogos realizadas por PérezEmbid, los recorridos de él mismo por las salas del Ermitage y las consultas con los servicios técnicos del propio museo fueron en vano ${ }^{2}$. Cuando publicó en 1972 su discurso de recepción en la Real Academia de Bellas Artes de San Femando, titulado " Pedro Millán y los orígenes de la escultura en Sevilla", a la obra de la

1. TORMO, E.: "Excursiones en la provincia de Huelva" en Boletín de la Sociedad Española de Excursiones. Arte, Arqueología e Historia Vol. 33. Madrid 1925. Pg.117.

2. PÉREZ EMBID, Fl.: Pedro Millán y los origenes de la escultura en Sevilla. Real Academia de Bellas Artes de San Fernando. Madrid, 1972. Pg. 58. 
Lamentación sólo pudo realizarle una análisis crítico a través de una mediocre fotografía, que María Elena Gómez-Moreno había recogido en su obra " Breve Historia de la escultura española " 3 . A partir de esos momentos, el grupo escultórico de la Lamentación se da por desaparecido.

Afortunadamente después de veintidós largos años hoy puede afirmarse que el imaginero Pedro Millán tiene un lugar en el catálogo de la colección de esculturas del magnífico museo del Ermitage. La fecha de ingreso del grupo escultórico de la Lamentación consta ser del año 1919, dos años más tarde de la Revolución de Octubre. Pero, persistió su antigua clasificación de obra alemana de autor desconocido, ya que la firma de Pedro Millán se consideró por muchos años como una inscripción gótica de carácter ilegible ${ }^{4}$. Estas circunstancias perjudicarían indudablemente a la búsqueda de la obra emprendida por PérezEmbid, ya que la visita de Tormo al Palacio de Mármol, con el consiguiente reconocimiento de la misma, no debió trascender.

Sin embargo, cabe plantearse las causas que motivaron esta pérdida de referencias sobre el grupo de La Lamentación. En tierras rusas la obra perdió su identidad, a pesar de que en España estuvo claramente catalogada hasta que su propietario el deán López Cepero, que la había comprado en Aracena en el año 1880, la vendió ocho años más tarde al Gran Duque Constantino de Rusia. Se sabe que el coleccionista con anterioridad la había ofrecido a la Diputación Provincial de Sevilla para que engrosara los fondos del Museo de Bellas Artes y cuesta trabajo pensar como no se llegó a realizar la compra, a pesar de que José de Gestoso la había enaltecido en 1884 en su obra " Pedro Millán. Ensayo biográfico crítico " 5 . Todo parece apuntar a que la obra, al haber estado tantos años, en la iglesia del Castillo de Aracena, debió perder allí su valiosa identidad, ante la ignorancia y la indiferencia del momento por la conservación del Patrimonio Artístico español.

Importante es también analizar el coleccionismo ruso de finales del siglo XIX. Desde el siglo XVIII se estaban adquiriendo esculturas para la ornamentación de los palacios imperiales de Rusia. Estas obras iban siendo almacenadas en la Gruta, Pabellón del famoso parque de Tsarskoye Selo, cerca de San Petesburgo. La construcción del Nuevo Ermitage en 1840-1849 vino a impulsar aún más el coleccionismo de esculturas de carácter ornamental. Dimitry Tatishchev, que murió en 1846, donó al Ermitage la magnífica colección de bronces italianos renacentistas y barrocos. En 1880 se adquirió la soberbia colección de Alexandre Basilewsky, que había pasado muchos años en Francia coleccionando esculturas y objetos suntuarios del siglo XV y XVI. De esta manera, siguiendo el gusto de la familia imperial rusa, muchos nobles se aficionaron a la escultura europea. La colección

3. GÓMEZ-MORENO, M E.: Breve Historia de la Escultura Española Madrid 1951. Fig. 120.

4. KOSAREVA, N.: Western european sculpture from Soviet Museums. 15th and 16th centuries. Leningrado, 1988. Pg.166.

5. GESTOSO, J.: Pedro Millán. Ensayo biográfico crítico. Sevilla, 1884. Pg.59. 
Viazaemsky incorporó algunas esculturas de Gótico tardío y del Renacimiento que provenían del norte de Europa ${ }^{6}$. Al final del siglo XIX se configuraron impresionantes colecciones de escultura no sólo en San Petesburgo, sino también en Moscú, así como en la ciudad de Kiev. A estas circunstancias puede deberse la compra de la Lamentación de Pedro Millán por el Gran Duque Constantino de Rusia.

No obstante, es aún más oscuro el aspecto que presenta la salida de la obra de la Catedral de Sevilla. Su primitivo lugar de emplazamiento fue la Capilla de San Laureano. El cabildo catedralicio aprueba la dotación del altar en el año 1485 al racionero Antonio Imperial ${ }^{7}$, que debió contratar con Pedro Millán los grupos escultóricos que lo iban a configurar: El Cristo Varón de Dolores, La Lamentación y El Entierro de Cristo. El propio racionero sería representado en el grupo escultórico principal, a modo de donante, a los pies de la imponente imagen del Cristo Varón de Dolores.

En la Catedral de Sevilla debieron permanecer estas primeras obras de Pedro Millán hasta el último cuarto del siglo XVIII, fecha en la que tanto Ponz ${ }^{8}$ como Ceán ${ }^{9}$ dan referencia de que tan sólo existían en la capilla de San Laureano dos grupos escultóricos: el Cristo Varón de Dolores y El Entierro de Cristo. Luego vendría la separación del resto del conjunto, a comienzos del siglo XIX, según apuntó González de León ${ }^{10}$. El Cristo Varón de Dolores y El Entierro de Cristo fueron localizados por Francisco Murillo Herrera en la iglesia de El Garrobo, pueblo de la provincia de Sevilla, pasando las dos esculturas, en el año 1970, al Museo Provincial de Bellas Artes ". El grupo de La Lamentación fue a parar a la provincia de Huelva, a la iglesia de Aracena, en donde lo pudo adquirir el coleccionista López Cepero en 1880.

Solamente resta hacer algunas puntualizaciones que vendrían a complementar algunos aspectos apuntados por Florentino Pérez-Embid. En principio plantear que los tres grupos escultóricos son el desarrollo sucesivo de un mismo tema iconográfico, en clara relación con la llamada "representación continua" de los misterios medievales. Hay una correspondencia estilística entre ambos, que evidencia que Pedro Millán debió realizar los tres grupos escultóricos entre 1485 y 1503, fechas de dotación de la capilla y del fallecimiento del donante, respectivamente.

Sin embargo, a la vista de la obra, no participamos de la hipótesis planteada por Pérez-Embid cuando afirma que La Lamentación puede ser una mera versión o esbozo del Entierro de Cristo. Es indudable que pudo llegar a esta conclusión

6. LIEBMANN, M.: Western european sculpture from Soviet Museum. 15th and 16th centuries Leningrado, 1988. Pg.5.

7. ANGULO, D.: La escultura en Andalucía 3 Vol. Laboratorio de Arte. Sevilla. Antes de 1936.

8. PONZ, A.: Viaje de España. Vol. IX. Madrid, 1780. Pg. 20.

9. CEÁN BERMÚDEZ, A.: Descripción artística de la Catedral de Sevilla. Sevilla, 1804. Pg.81

10. GONZÁLEZ DE LEÓN, F.: Noticia artística, histórica y curiosa de todos los edificios...de Sevilla. Tomo II, Sevilla, 1844. Pg. 77.

11. PAREJA, E.: Museo de Bellas Artes de Sevilla Tomo I, Sevilla, 1991. Pg.80 
tras haber analizado la obra a través de una mediocre fotografía. El grupo escultórico rezuma por su calidad y expresividad su condición de obra original, con idéntico tratamiento del modelado que El Cristo Varón de Dolores. Las analogías estilísticas de las dos obras son lo suficientemente evidentes como para apuntar que se realizaron en el mismo periodo. No así se puede decir del Entierro de Cristo, que muestra un tratamiento de las formas mucho más minucioso, más barroquizante, mucho más efectista, a diferencia de los volúmenes agudos y limpios en sus aristas que manifiestan las obras más tempranas de Pedro Millán, al transportar al barro el tratamiento de la talla en madera. No en vano, en las nóminas de operarios de la Catedral de Sevilla consta el artista como entallador, ligado a los trabajos de madera y piedra. ${ }^{12}$

Actualmente, La Lamentación aparece en el Ermitage catalogada con el número de inventario $\mathrm{N}$. H. ck. 1.425 . Su altura es de $52 \mathrm{cms}$ y su anchura es la de $105 \mathrm{cms}$. Al igual que los otros grupos escultóricos arriba mencionados está realizada en barro cocido y policromado. La parte posterior de la obra no se halla modelada, como ocurre en El Entierro de Cristo, presentando un gran orificio en el centro, necesario para una buena cochura en el horno. El grupo escultórico muestra también restos de policromía, especialmente visible en la profundidad de los pliegues de los ropajes. Estos restos demuestran que el grupo escultórico tuvo una imprimación de yeso blanco, sobre la que se le aplicó la capa de oro y sobre ella los pigmentos coloreados. Ha sido muchas veces renovada esta policromía y por desgracia no se conserva la que tuvieron los rostros. La filacteria que recoge la firma del autor y que está colocada bajo el rostro yacente de Cristo reproduce como es habitual la inscripción de P. MILLĀ IMAG.

12. MORÓN DE CASTRO, M.F.: " Análisis histórico estilístico del Retablo Mayor de la Catedral de Sevilla " en El Retablo Mayor de la Catedral de Sevilla. Estudios e investigaciones realizadas con motivo de su restauración Sevilla, 1981. Pg.133. 


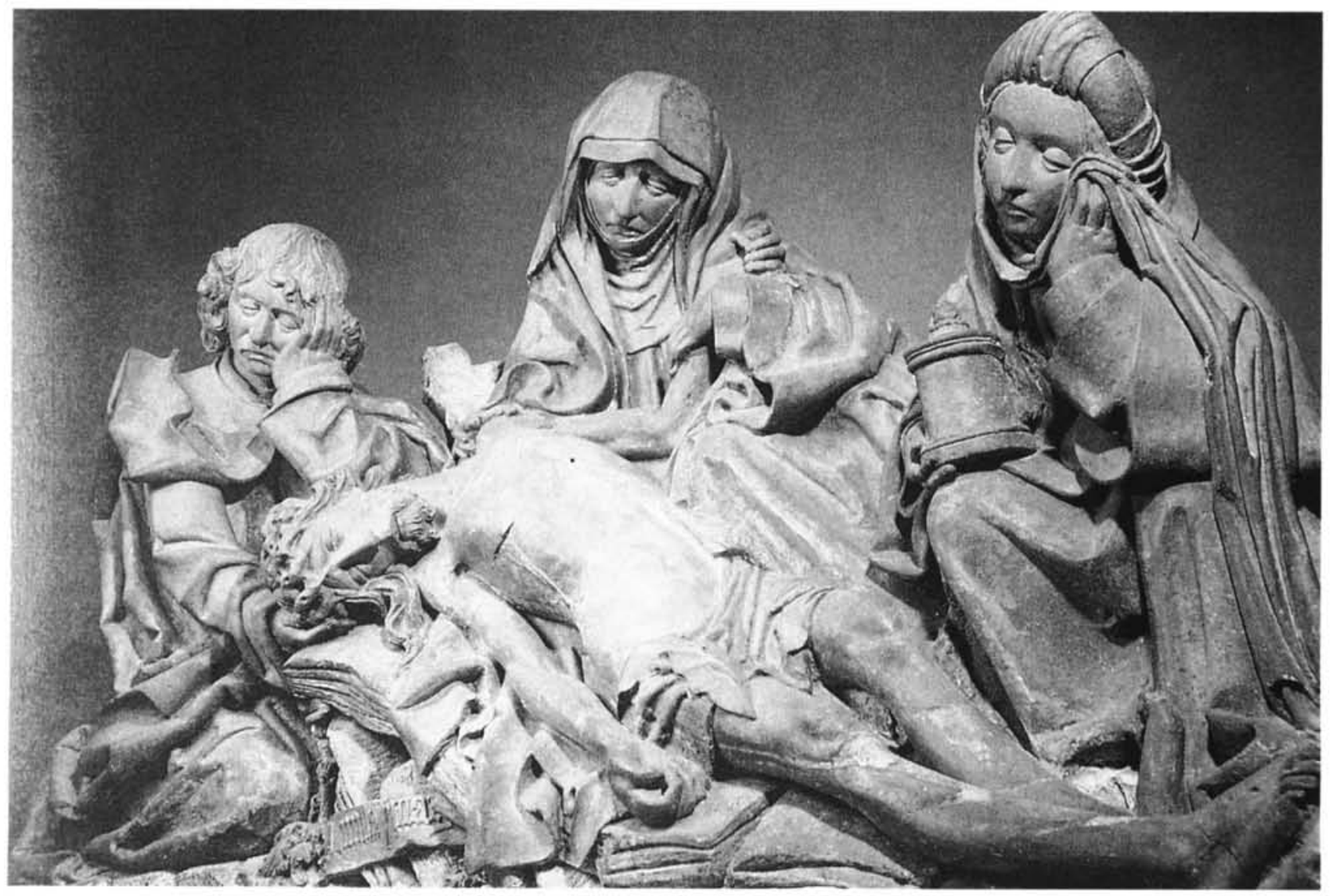

PEDRO MILLÁN: La Lamentación. 1485-1503. Barro cocido y policromado. $105 \mathrm{cms}$ x x $52 \mathrm{cms}$. Museo del Ermitage. San Petesburgo. 


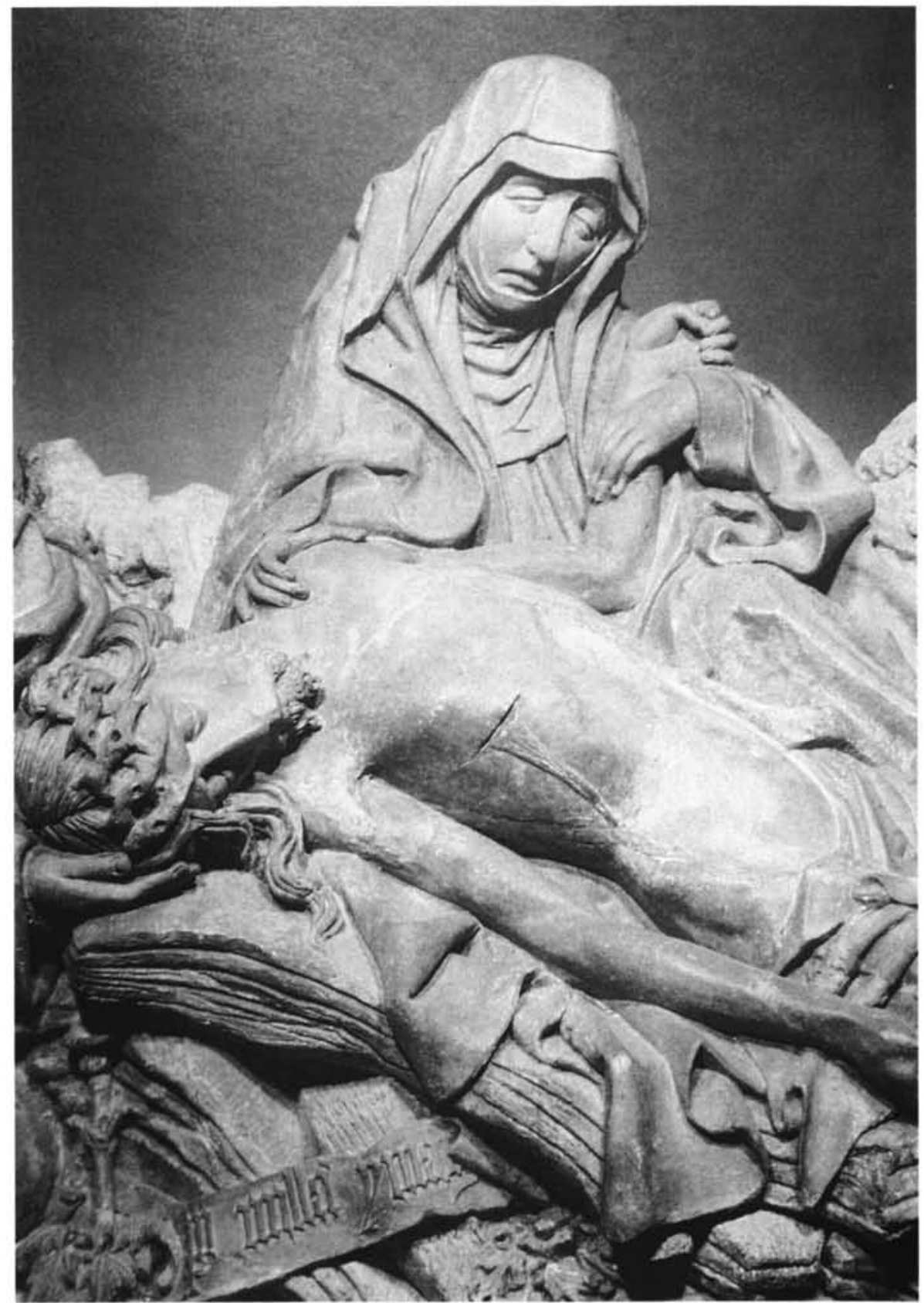

PEDRO MILLÁN: Detalle de la firma del autor. Museo del Ermitage. 